\title{
Erratum to: Hierarchical spatial genetic structure in a distinct population segment of greater sage-grouse
}

\author{
Sara J. Oyler-McCance • Michael L. Casazza • \\ Jennifer A. Fike $\cdot$ Peter S. Coates
}

Published online: 18 July 2014

(C) Springer Science+Business Media Dordrecht 2014

\section{Erratum to: Conserv Genet}

\section{DOI 10.1007/s10592-014-0618-8}

Unfortunately, Fig. 5 has been published incorrectly (the polygons were missing) in the original publication. The corrected Fig. 5 is published below.

The online version of the original article can be found under doi:10. 1007/s10592-014-0618-8.

\section{S. J. Oyler-McCance $(\bowtie) \cdot$ J. A. Fike}

Fort Collins Science Center, U.S. Geological Survey, 2150

Centre Avenue, Building C, Fort Collins, CO 80526, USA

e-mail: soyler@usgs.gov

M. L. Casazza · P. S. Coates

Western Ecological Research Center, U.S. Geological Survey,

Dixon Field Station, 800 Business Park Drive, Dixon, CA, USA 
Fig. 5 Factorial components analysis of Bi-State and neighboring populations of greater sage-grouse using 14 microsatellite loci. Samples in the red polygon represent the individuals in the neighboring populations of Churchill and Lassen. Samples in the blue polygon represent a subset of individuals from the PN

sampling locale (PNa). Samples in the green polygon represent the remaining samples in the $\mathrm{Bi}$ State. The individuals within the green polygon that are pink are from the WM sampling locale (Color figure online)

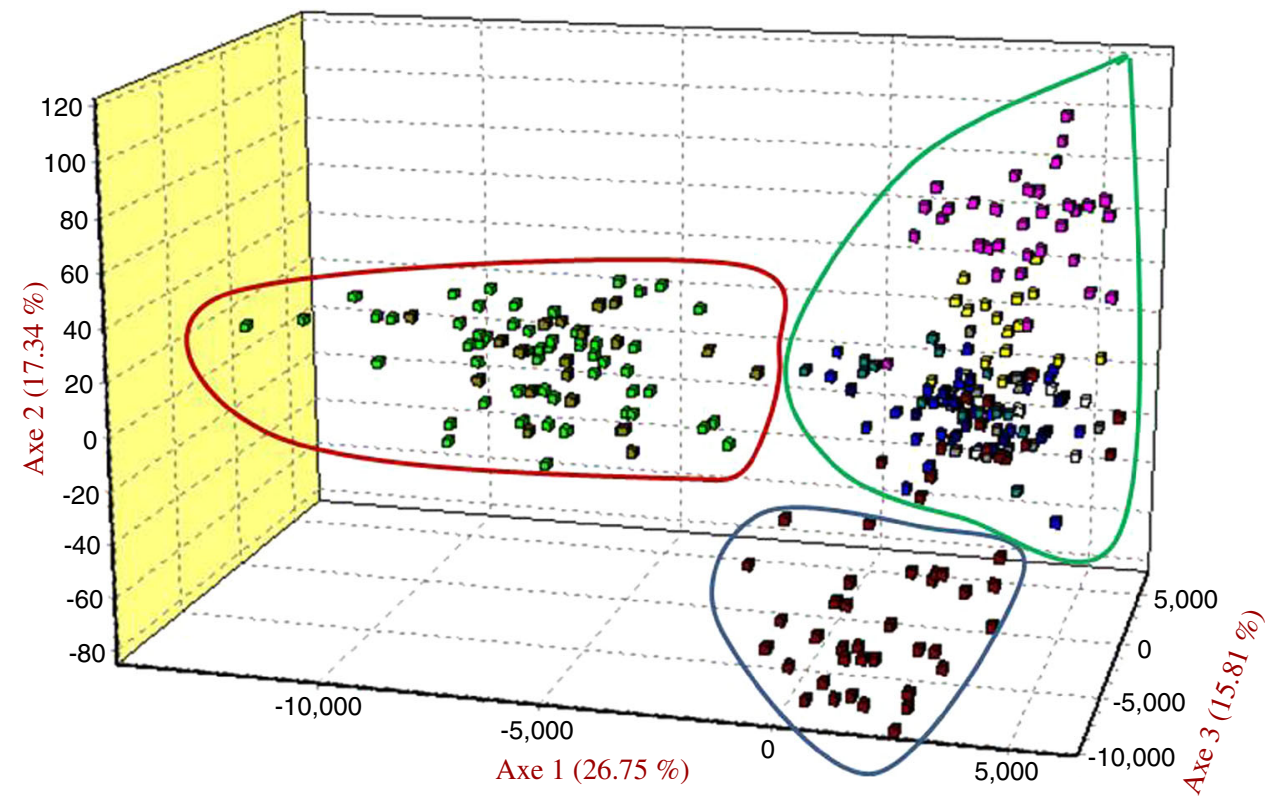

